\title{
Aneurisma subclavio congénito en un paciente pediátrico
}

\section{Congenital subclavian artery aneurism in a pediatric patient}

\author{
Rocío A. Peña-Juárez ${ }^{1 *}$, Miguel A. Medina-Andrade², David Ramírez-Cedillo², Andrés Landeros ${ }^{1}$ y \\ Juan P. Abarca-De la Paz
}

${ }^{1}$ Servicio de Cardiología Pediátrica, Hospital Civil de Guadalajara Fray Antonio Alcalde; ${ }^{2}$ Servicio de Cirugía de Tórax y Cardiovascular, Hospital Civil de Guadalajara Fray Antonio Alcalde; ${ }^{3}$ Servicio de Cardiología Pediátrica, Centro Médico de Occidente. Zapopan, Jalisco, México

Los aneurismas de la arteria subclavia son extremadamente raros, con una incidencia reportada por diferentes autores que oscila entre el $0.01 \%$ y el $3.5 \%{ }^{1}$. En una serie reportada por Dent, et al. ${ }^{2}$ de 1488 pacientes con aneurismas ateroescleróticos solo se encuentran dos aneurismas de la arteria subclavia. Su baja frecuencia se refleja en los pocos casos reportados en la literatura, y en la etapa pediátrica no se encontró ninguno.

Las principales causas de aneurisma de la arteria subclavia son la degeneración ateroesclerótica de la pared arterial, el síndrome de salida del tórax y el trauma secundario a herida por proyectil de arma de fuego, fractura de clavícula o iatrogénico'. En la etapa pediátrica, los aneurismas más frecuentes se localizan en la aorta o las coronarias, y son secundarios a infecciones o enfermedades reumatológicas. Las complicaciones dependen principalmente de la localización, pero entre las más frecuentes se reportan compresión del plexo braquial o de los vasos de las extremidades superiores que puede conducir a edema ${ }^{3}$. Existen técnicas quirúrgicas endovasculares para su manejo; sin embargo, se refieren menos de 100 informes de reparación endovascular de aneurismas de subclavia, con una tasa de complicaciones del $28 \%$ y una mortalidad del $5 \%{ }^{4}$.

Presentamos el caso de un lactante de 1 año y 8 meses de edad que acudió a revisión por la presencia

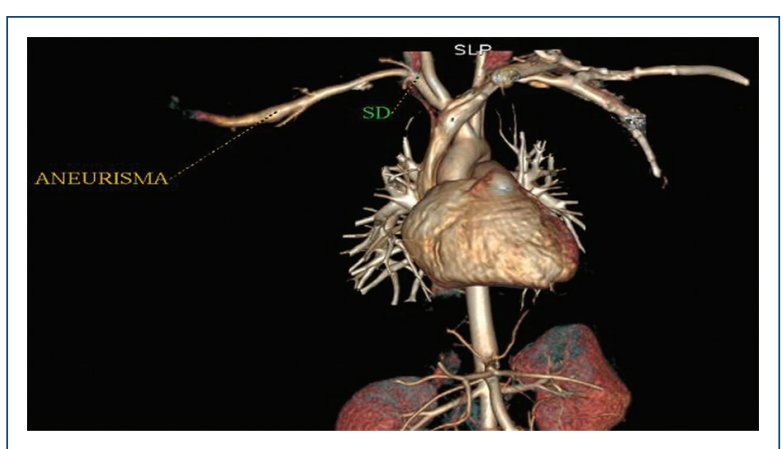

Figura 1. Aneurisma sacular de la subclavia derecha, aproximadamente a $55 \mathrm{~mm}$ de su origen. SD: subclavia derecha.

de una masa pulsátil desde el periodo neonatal. Las imágenes obtenidas por tomografía computarizada multidetector de 64 cortes, realizada con protocolo de baja dosis ( $80 \mathrm{kV}, 50 \mathrm{~mA}$ ), muestran un aneurisma sacular en la arteria subclavia derecha, a $55 \mathrm{~mm}$ de su origen (Fig. 1), con un diámetro de $6.8 \times 7 \mathrm{~mm}$ y $\sin$ evidencia de trombos en su interior (Figs. 2 y 3). La subclavia izquierda se encuentra sin evidencia de estenosis ni aneurismas (Fig. 4) y la aorta sin signos de aortitis. Se descartaron todas las causas probables infecciosas, reumatológicas y hematológicas, por lo
Correspondencia:

${ }^{*}$ Rocío A. Peña-Juárez E-mail: alepejz@gmail.com
Disponible en internet: 19-03-2021 Arch Cardiol Mex. 2021;91(4):514-515
Fecha de aceptación: 15-02-2021 DOI: $10.24875 /$ ACM. 20000543 www.archivoscardiologia.com

1405-9940 / @ 2021 Instituto Nacional de Cardiología Ignacio Chávez. Publicado por Permanyer. Este es un artículo open access bajo la licencia CC BY-NC-ND (http://creativecommons.org/licenses/by-nc-nd/4.0/). 


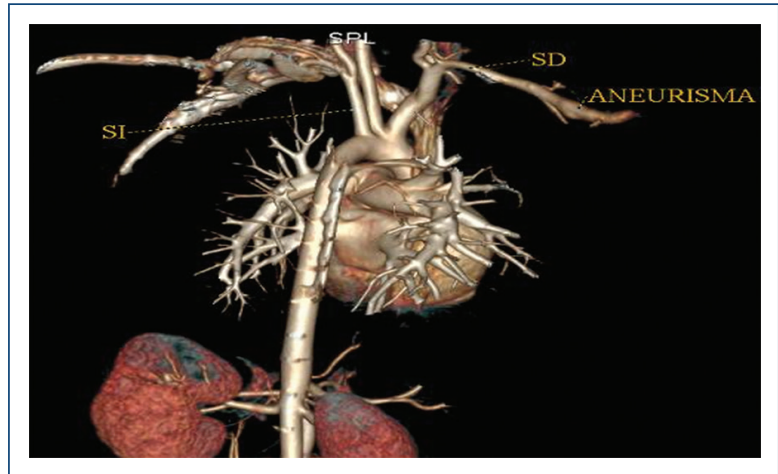

Figure 2. Aneurisma de la subclavia derecha sin evidencia de trombos en su interior. SD: subclavia derecha; Sl: subclavia izquierda.

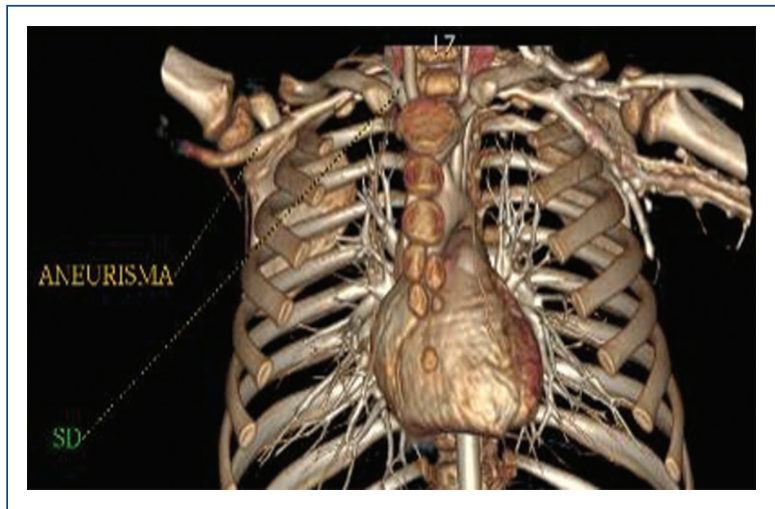

Figura 4. Subclavia izquierda sin presencia de aneurismas y aorta sin datos de aortitis. SD: subclavia derecha.

que se consideró congénito. Actualmente se encuentra en espera de realizar manejo quirúrgico.

\section{Financiamiento}

Ninguno.

\section{Conflicto de intereses}

Ninguno.

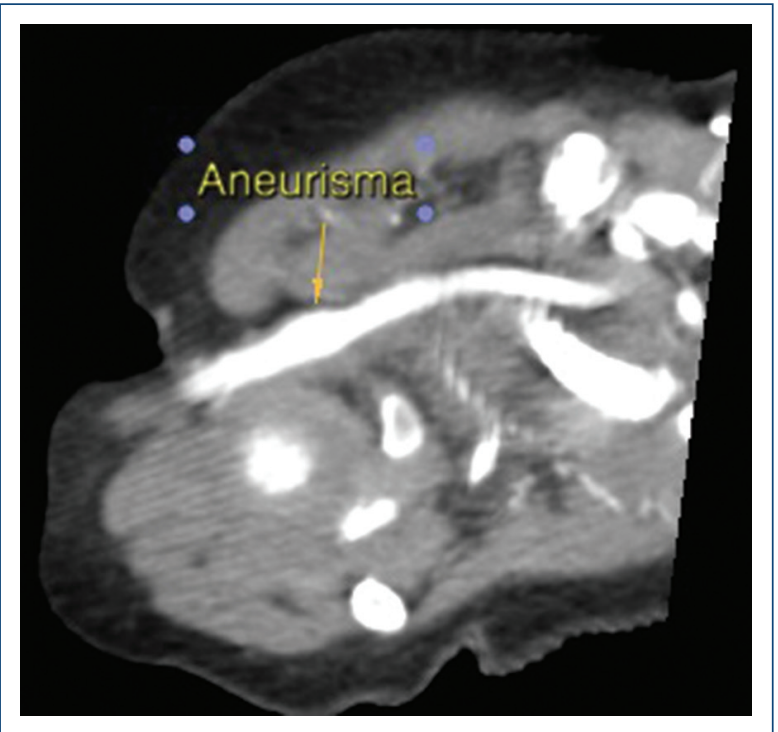

Figure 3. Imagen longitudinal sin evidencia de trombos en su interior.

\section{Responsabilidades éticas}

Protección de personas y animales. Los autores declaran que para esta investigación no se han realizado experimentos en seres humanos ni en animales.

Confidencialidad de los datos. Los autores declaran que han seguido los protocolos de su centro de trabajo sobre la publicación de datos de pacientes.

Derecho a la privacidad y consentimiento informado. Los autores han obtenido el consentimiento informado de los pacientes y/o sujetos referidos en el artículo. Este documento obra en poder del autor de correspondencia.

\section{Bibliografía}

1. Gaitán JA, Gómez CE. Aneurisma de la arteria subclavia. Rev Colom Cir. 2015;30:68-73.

2. Dent TL, Lindenauer SM, Ernst CB, Fry WJ. Multiple arteriosclerotic arterial aneurysms. Arch Surg. 1972;105:338-43.

3. Singh $\mathrm{Y}$, Verma $\mathrm{H}$, Tripathi R. Giant subclavian artery aneurysm: case report and review of literature. Indian J Vasc Endovasc Surg. 2017;4:73-5.

4. Mohan IV, Stephen MS. Peripheral arterial aneurysms: open or endovascular surgery? Prog Cardiovasc Dis. 2013;56:36-56. 